\title{
Larva migrans cutânea: ocorrência de casos humanos e identificação de larvas de Ancylostoma spp em parque público do município de Taciba, São Paulo
}

\author{
Cutaneous larva migrans: reports of pediatric cases and contamination \\ by Ancylostoma spp larvae in public parks in Taciba, São Paulo State
}

\author{
Vamilton Alvares Santarém ${ }^{1}$, Rogério Giuffrida ${ }^{1}$ e Gabriel Arantes Zanin ${ }^{2}$
}

\begin{abstract}
RESUM0
Descreve-se a ocorrência de larva migrans cutânea em crianças de Taciba, São Paulo, Brasil, pelo contato com areia de parques públicos, onde observou-se larvas de Ancylostoma spp. A enfermidade foi controlada após adotar-se medidas educacionais sanitárias, desativação e isolamento dos locais para reduzir acesso de animais e troca de areia.
\end{abstract}

Palavras-chaves: Ancylostoma. Larva migrans. Zoonoses. Parque Público.

\begin{abstract}
Cutaneous larva migrans in children from Taciba, São Paulo, Brazil, was related to contact with sand in public squares, where Ancylostoma spp larvae were detected. The outbreaks were controlled by sanitary education, temporary deactivation and isolation of the squares in order to impede the access of animals and substitution of the sand.
\end{abstract}

Key-words: Ancylostoma. Larva migrans. Zoonosis. Public squares.

0 solo de praças e parques públicos constitui via de transmissão para zoonoses parasitárias, uma vez que a eliminação de fezes por carnívoros domésticos que têm acesso aos locais de recreação pública pode resultar na contaminação por ovos de helmintos. Um dos mais freqüentes é 0 Ancylostoma spp, um geohelminto que parasita cães e gatos e, eventualmente, afeta seres humanos, provocando a larva migrans cutânea (LMC).

A LMC é decorrente do contato direto da pele do ser humano com a larva do terceiro estádio de Ancylostoma spp, presente no solo ou em fômites contaminados com fezes de cães ${ }^{1}$. Após penetração na epiderme, as larvas migram no tecido subcutâneo ocasionando reações inflamatórias caracterizadas por prurido intenso e erupções de aspecto serpiginoso, observadas mais freqüentemente nos membros inferiores, principalmente nos pés, nádegas e mãos ${ }^{112}$, e, menos comumente, em outras regiões como o couro cabeludo ${ }^{10} \mathrm{e} \mathrm{face}^{5}$.

A enfermidade tem sido registrada em diversos países, principalmente naqueles de clima subtropical e tropical. № Brasil, é causada pelas larvas de Ancylostoma braziliense e A. caninum, sendo mais freqüente na região litorânea ${ }^{13}$.

Embora não ocorra distinção quanto a raça, sexo ou idade para a síndrome da LMC, seu potencial zoonótico é maior para crianças, que são mais expostas ao brincarem com solo de locais que podem estar contaminados, como praias e caixas de areia de parques de recreação $0^{1}$.

0 objetivo dos autores deste artigo é 0 de relatar a ocorrência de larvas de Ancylostoma spp em solo de parque público peridomiciliar do município de Taciba, São Paulo, Brasil, e de LMC em crianças do município.

1. Laboratório de Medicina Veterinária Preventiva e Saúde Pública do Hospital Veterinário da Universidade do Oeste Paulista, Presidente Prudente, SP. 2. Laboratório de Patologia Clínica Veterinária do Hospital Veterinário da Universidade do Oeste Paulista, Presidente Prudente, SP.

Endereço para correspondência: Dr. Vamilton Alvares Santarém. Hospital Veterinário/UNOESTE, Rodovia Raposo Tavares, Km 572, Bairro Limoeiro, 19001-970 Presidente Prudente, São Paulo, Brasil.

Fax: 5518 229-2036

e-mail: vamilton@ vet.unoeste.br

Recebido para publicação em 10/9/2002

Aceito em 13/2/2004 


\section{RELATO DOS CASOS}

No município de Taciba, região Oeste do Estado de São Paulo, foram observados pelos agentes de saúde do referido município, no ano de 2001, três casos de dermatite em crianças com aproximadamente 10 anos de idade. As dermatites apresentavam-se como lesões serpiginosas, com áreas de eritema e prurido intenso, principalmente na região do membro inferior dos pacientes. 0 diagnóstico foi confirmado pelos médicos do município como LMCe 0 tratamento prescrito aos pacientes, à base de tiabendazole, resultou na regressão das lesões e cura.

Em outubro do mesmo ano, a Secretaria Municipal de Saúde de Taciba solicitou ao Núcleo de Medicina Veterinária Preventiva e Saúde Pública do Curso de Medicina Veterinária da Universidade do Oeste Paulista, Presidente Prudente, São Paulo, a colaboração para investigação dos prováveis focos de contaminação e elaboração de medidas de controle aplicáveis ao município.

Durante a investigação, os agentes de saúde relataram que entre 1999 e 2001 ocorreram a cada mês 4 a 7 casos de LMC, respectivamente, no inverno e no verão, indicando a ocorrência de surtos no município.

Após mapeamento dos possíveis focos de contaminação, resolveu-se investigar o parque de recreação pública peridomicilar às residências das crianças acometidas e frequientado pelas mesmas. O local, utilizado para fins esportivos, com quadras de voleibol e futebol, e área de lazer para crianças, era constituído por caixas de areia como piso, em um total de quatro. Verificou-se que os cães e gatos errantes e domésticos tinham livre acesso a essas caixas, 0 que justificou a pesquisa de ovos e larvas de helmintos no solo.

Para pesquisa de larvas de helmintos, foram colhidos aproximadamente $200 \mathrm{~g}$ de solo de cinco pontos diferentes de cada caixa, com auxílio de uma colher-de-jardineiro, em uma profundidade de cinco centímetros da superfície, evitando-se a colheita de fezes e solo em um raio de um metro de distância do material fecal. As amostras foram acondicionadas em sacos plásticos e mantidas sob refrigeração $\left(4^{\circ} \mathrm{C}\right)$ até 0 momento do processamento.

Para recuperação de larvas foi adotado o método de Baermann modificado e para a pesquisa de ovos de helmintos realizou-se a técnica de centrífugo-flutuação em solução de dicromato de sódio ( $d=1.350$ ) descrita por Dada ${ }^{9}$, utilizando-se 30 e $10 \mathrm{~g}$ de cada uma das amostras colhidas, respectivamente. Aleitura do material foi feita por microscopia ótica (objetiva de 10X), sendo observadas duas lâminas para cada amostra. A identificação das larvas foi realizada adotando-se as características morfométricas ${ }^{616}$.

Foi verificada a presença de larvas de Ancylostoma spp nas amostras obtidas do campo de futebol e da área de lazer infantil, observando-se pelo menos uma larva em cada lâmina. Não foi recuperado nenhum ovo de Toxocara ou oocistos de protozoários nas amostras examinadas.

\section{DISCUSSÃ0}

A observação de larvas de Ancylostoma spp e de cães e gatos no parque peridomiciliar aos pacientes acometidos representava risco potencial para a população, especialmente para as crianças que tinham acesso ao local. A predisposição para o desenvolvimento de LMCem crianças está associada à exposição ao solo contaminado ${ }^{1}$ de parques infantis de escolas ${ }^{4}$ e praias 5 . № Brasil, pesquisadores têm descrito a contaminação por ovos e/ou larvas de helmintos causadores de larva migrans em solos de parques públicos ${ }^{2367915}$ e escolas infantis ${ }^{414}$.

Com base nos achados, recomendou-se 0 isolamento do parque público para troca de areia ou pavimentação das caixas e a instalação de telas ao redor do parque para dificultar 0 acesso de cães e gatos. Essas medidas são indicadas para a profilaxia de zoonoses obtidas pelo contato com 0 solo ${ }^{4}$. Foi adotada também uma política voltada para a educação da comunidade e a continuidade das medidas de vigilância epidemiológica empregadas pela Secretaria de Saúde.

Após implementação das medidas recomendadas, houve desativação temporária e troca da areia de todos os parques públicos da cidade e orientação da população sobre o problema, o que resultou na redução do registro de novos casos. Planeja-se, ainda, 0 isolamento com tela dos parques de recreação com 0 objetivo de minimizar 0 acesso de animais e o risco da zoonose.

\section{REFERÊNCIAS BIBLIOGRÁFICAS}

1. Acha PN, Szyfres B. Zoonosis y enfermedades transmissibles al hombre y a los animales, $2^{\text {nd }}$ edition, Organización Mundial de la Salud, Washington, 1986.

2. Alcântara N, Bavia E, Silvão RM, Carvalho E. Environmental contamination by Toxocara sp eggs in public areas of Salvador, Bahia State, Brazil. Revista da Sociedade Brasileira de Medicina Tropical 22: 187-190, 1989.

3. Araújo FR, Araújo CP, Werneck MR, Górski A. Larva migrans cutânea em crianças de uma escola em área do Centro-Oeste do Brasil. Revista de Saúde Pública 34: 84-85, 2000.

4. Araújo FR, Crocci AJ, Rodrigues RGC, Avalhaes J da Silva, Miyoshi MI, Salgado FP, da Silva MA, Pereira ML. Contaminação de praças públicas de Campo Grande, Mato Grosso do Sul, Brasil, por ovos de Toxocara e Ancylostoma em fezes de cães. Revista da Sociedade Brasileira de Medicina Tropical 32: 581-583, 1999.

5. Bouchaud O, Houzé S, Schiemann R, Durand R, Ralaimazava P, Ruggeri C, Coulaud JP. Cutaneous larva migrans in travelers: a prospective study with assessment of therapy with ivermectin. Clinical Infectious Diseases 31: 493498, 2000 .

6. Bowman DD. Diagnostic Parasitology. In: Bowman DD (ed) Georgis' parasitology for veterinarians, $6^{\text {th }}$ edition, WB Saunders, Philadelphia, p. 293-405, 1995

7. Chieffi PP, Muller, EE. Prevalência de parasitismo por Toxocara canis em cães e presença de ovos de Toxocara sp no solo de localidades públicas da zona urbana do município de Londrina, Estado do Paraná, Brasil. Revista de Saúde Pública 20: 367-372, 1976.

8. Corrêa GLB, Michelon E, Lagaggio VRA, Moreira WS, Moraes RQ, Leite CR, Ribas HO, Adamy M, Pit GL, Colombo FH. Contaminação do solo por ovos, larvas de helmintos e oocistos de protozoários, em praças públicas de Santa Maria e sua importância em saúde pública. Revista Brasileira de Parasitologia Veterinária 4: 137, 1995.

9. Dada BJO. A new technique for the recovery of Toxocara eggs from soil. Journal of Helminthology 53: 141-144, 1979.

10. Guimarães LC, Silva JH, Saad K, Lopes ER, Meneses ACO. Larva migrans within scalp sebaceous gland. Revista da Sociedade Brasileira de Medicina Tropical 32: 187-189, 1999.

11. Lima WS, Camargo MCV, Guimarães MP. Surto de larva migrans em uma creche de Belo Horizonte, Minas Gerais (Brasil). Revista do Instituto de Medicina Tropical de São Paulo 26: 122-144, 1984. 
12. Mattone-Volpe F. Cutaneous larva migrans infection in the pediatric foot. A review and two case reports. Journal of the American Pediatric Medical Association 88: 228-231, 1998

13. Moraes RG, Leite IC, Goulart EG. Parasitologia Médica. Livraria Atheneu, Porto Alegre, p. 263-274, 1971.

14. Nunes CM, Pena, FC, Negrelli, GB, Anjo, CGS, Nakano, MM, Stobbe, NS. Ocorrência de larvas de larva migrans na areia de áreas de lazer das escolas municipais de ensino infantil, Araçatuba, SP, Brasil. Revista de Saúde Pública 34: 656-658, 2000.

15. Santarém VA, Sartor IF, Bergamo FMM. Contminação por ovos de Toxocara spp, de parques e praças públicas de Botucatu, São Paulo, Brasil. Revista da Sociedade Brasileira de Medicina Tropical 31: 529-532, 1998.

16. Williams JF, Zajac A. Diagnosis of gastrointestinal parasitism in dogs and cats. Ralston Purina, Saint Louis, 1980. 